\title{
Topical Treatment with Bergamot Flavonoid-Based Gel in Post-Surgical Wounds after Hemorrhoidectomy: Preliminary Results
}

\author{
Dott. Danilo Cafaro ${ }^{* 1,2}$, Dott Alessandro Sturiale ${ }^{1}$, Dottssa Maria Stefania Sinicropi ${ }^{3}$, Dott. Luciano Onofrio ${ }^{4}$, \\ Alessia Catalano ${ }^{5}$, Prof. Gabriele Naldini ${ }^{1}$ \\ ${ }^{1}$ Proctological and Perineal Surgical Unit, Cisanello Hospital of Pisa, University Hospital of Pisa, Pisa, Italy; \\ alexstur@yahoo.it (N.G.) (A.S.) \\ ${ }^{2}$ Proctology Surgery, Tropea Hospital, Vibo Valentia, Italy (VV), Italy; danilo.cafaro@ tiscalinet.it (D.C.) \\ ${ }^{3}$ Department of Pharmacy, Health and Nutritional Sciences, University of Calabria, 87036 Arcavacata di Rende, \\ Italy; s.sinicropi@unical.it (M.S.S.) \\ ${ }^{4}$ Department of General, Oncological and Laparoscopic Surgery, Civil Hospital A.G.P. Piedimonte Matese (CE), \\ 81016, Italy; luciano.onofrio@ libero.it (L.C.) \\ ${ }^{5}$ Department of Pharmacy-Drug Sciences,) University of Bari “Aldo Moro”, 70126 Bari, Italy; \\ alessia.catalano@uniba.it (A.C.) \\ *Correspondence: Dott. Danilo Cafaro; danilo.cafaro@tiscalinet.it
}

Received 13 December 2021;

Accepted 26 December 2021;

Published 01 January 2022

\begin{abstract}
Background: Haemorrhoidal Disease (HD) is a very diffuse anorectal condition that involves a large part of the population, both male and female of every age. Among the several procedures proposed to treat HD, conventional excisional surgery remains one of the most performed, it is characterized by important post-operative pain whose historical knowledge often scare the patients. The pain is mainly related to the anal wounds and the healing speed surely influence the post-operative course. The aim of this study was to evaluate the effect of using Benebeo Gel ${ }^{\circledR}$ on post-operative wound healing after open haemorrhoidectomy. Methods and Results: This was an observational prospective study conducted in the Proctological and Pelvic Floor Clinical Centre (PPFCC) of the University Hospital of Pisa. From April 2019 to January 2020 all the 175 patients aged between 18 and 75 undergone to open hemorrhoidectomy were enrolled. The post-operative follow-up was scheduled as follows: 7 day, 15 day, 22 days and 30 days after surgery. The primary end point was: time taken to get complete wound healing with a reepithelized tissue. Secondary endpoints were: evaluate post-operative pain using VAS scale, bleeding, discharge and overall patients satisfaction about the procedure and the topical gel. All the patients were instructed to take topical gel by using the cannula provided with the product put it into the finger phalanx and then upon injured area twice a day (once in the morning after defecation and once before sleeping) for 25 days after. The administration of the product begins in 4 th post-operative day. The mean post-operative pain at 7 days was $6 \pm 2$, at 15 days $4 \pm 1$ at 22 day 3 and at 30 days was $2 \pm 1$. The mean time to get complete wound healing was $23 \pm 4$ days. Conclusions: He present study aimed to evaluate the efficacy of a new topical gel mainly composed by bergamot-derived flavonoids and hyaluronic acid in patients treated with excisional hemorrhoidectomy. The results after 2 weeks of treatment seems to be promising with a very good clinical outcome and patient satisfaction within 1 month.
\end{abstract}

Keywords: hemorrhoidectomy, flavonoids, bergamotts, surgical wounds

\section{Introduction}

Haemorrhoidal Disease (HD) is a very diffuse anorectal condition that involves a large part of the population, both male and female of every age ${ }^{[1]}$.

The age mainly involved ranges between 45 and 65 years old with a peak at 45 and 55 years ${ }^{[2]}$. HD affects millions of people around the world reveling to be a major medical and socioeconomic problem ${ }^{[3]}$.

Topical and systemic medical treatment are recommended as first line treatment, but in case of failure or very symptomatic high-graded prolapse, surgery remains the main option ${ }^{[4]}$.

Among the several procedures proposed to treat $\mathrm{HD}$, conventional excisional surgery remains one of the most performed 
[5]. Although hemorrhoidectomy may be performed also using energy devices ${ }^{[6-8]}$ trying to reduce post-operative bleeding and pain, it is characterized by important post-operative pain ${ }^{[7]}$ whose historical knowledge often scare the patients. The pain is mainly related to the anal wounds and the healing speed surely influence the post-operative course.

Benebeo Gel ${ }^{\circledR}$ is an anal ointment made of Bergamot Polyphenolic Fraction, Pantenol, Sodio jaluronato and Gomma xantana indicated for anal and perianal inflammation. It stimulates and protects tissues repairing showing to have also a vasoprotective effect ${ }^{[9]}$.

The aim of this study was to evaluate the effect of using Benebeo Gel® on post-operative wound healing after open haemorrhoidectomy.

\section{Material and methods}

This was an observational prospective study conducted in the Proctological and Pelvic Floor Clinical Centre (PPFCC) of the University Hospital of Pisa. From April 2019 to January 2020 all the patients aged between 18 and 75 undergone to open hemorrhoidectomy were enrolled. The exclusion criteria were: concomitant anal disease or previous proctologic surgery which could influence the study, inflammatory bowel disease, previous local radiotherapy, HIV infection or neoplastic disease, pregnancy or breast feeding, oral anticoagulant therapy for any reason and poor general conditions which made the patient unable to understand the purpose and the aim of the study.

All the patients were preoperatively screened according the current guidelines evaluating also the bowel function. Digital exploration, anoscopy were always performed and transanal 3D $360^{\circ}$ ultrasound and coloscopy when required.

The procedures were performed both with electroscalpel and energy devices as the combination of ultrasound and bipolar energy.

The post-operative course was managed with a combination of paracetamol $1 \mathrm{gr}$ and ketorolac $30 \mathrm{mg}$ for 5 days and after as rescue therapy, in association with oral administration of diosmine $500 \mathrm{mg} 3$ times per day for 30 days to prevent post-operative haemorrhoidal acute complications.

The post-operative follow-up was scheduled as follows: 7 day, 15 day, 22 days and 30 days after surgery.

The primary end point was: time taken to get complete wound healing with a re-epithelized tissue.

Secondary endpoints were: evaluate post-operative pain using VAS scale, bleeding, discharge and overall patients satisfaction about the procedure and the topical gel.

\section{Topical product and its application}

Benebeo Gel ${ }^{\circledR}$ is a bergamot-derived gel whose pharmacological functions are: vasoprotective, reducing the permeability and the fragility of the endothelial layer, antioxidant, by reducing the cyclossigenasi type II production, anti-inflammatory, reducing the pro-inflammatory cytokines activation by inhibiting myeloperosides and so the nuclear translocation of NF-KB. A recent study conducted by a research group of the University of Cosenza UNICAL, Pharmacy and Nutraceutica Department, suggested that the antinflammatory function of Benebeo Gel ${ }^{\circledR}$ is due to reduction of the intracellular free radicals, in particular of the COX-2, and to the inhibition of prostaglandins and leukotriene [10].
All the patients were instructed to take topical gel by using the cannula provided with the product put it into the finger phalanx and then upon injured area twice a day (once in the morning after defecation and once before sleeping) for 25 days after. The administration of the product begins in 4th post-operative day.

\section{Results}

In the study period, $175(100 \mathrm{M}, 75 \mathrm{~F})$ patients were enrolled. The mean age was 47 years (range 18-75). Patients characteristics were reported in Table 1.

The mean post-operative pain at 7 days was $6 \pm 2$, at 15 days $4 \pm 1$ at 22 day 3 and at 30 days was $2 \pm 1$. The mean time to get complete wound healing was $23 \pm 4$ days. There were no cases of post-operative bleeding. All the patients referred a discharge resolution within 30 days with a significant reduction perceived within 15 days.

It was not found any difference in safety and efficacy between patients undergone two or three piles excision or between the two groups treated with or without energy devices.

All the patients were satisfied about the topical gel with a mean rate of $9 / 10$ while the mean satisfaction about the procedure and healing was 7/10. (Figure 1) (Figure 2)

Table 1: Patients' characteristics

\begin{tabular}{|c|c|}
\hline \multicolumn{2}{|l|}{ Patients } \\
\hline Age mean (range) & $47(18-75)$ \\
\hline Gender & 175 \\
\hline Male & 100 \\
\hline Female & 75 \\
\hline \multicolumn{2}{|l|}{ Bowel } \\
\hline Regular & 95 \\
\hline Constipation & 46 \\
\hline Diarrhea & 34 \\
\hline \multicolumn{2}{|l|}{ Goligher grade } \\
\hline II & 7 \\
\hline III & 65 \\
\hline IV & 103 \\
\hline \multicolumn{2}{|l|}{ Piles treated } \\
\hline 3 piles & 78 \\
\hline 2 piles & 49 \\
\hline 2 piles + mucopexy & 36 \\
\hline 3 piles + mucopexy & 12 \\
\hline
\end{tabular}

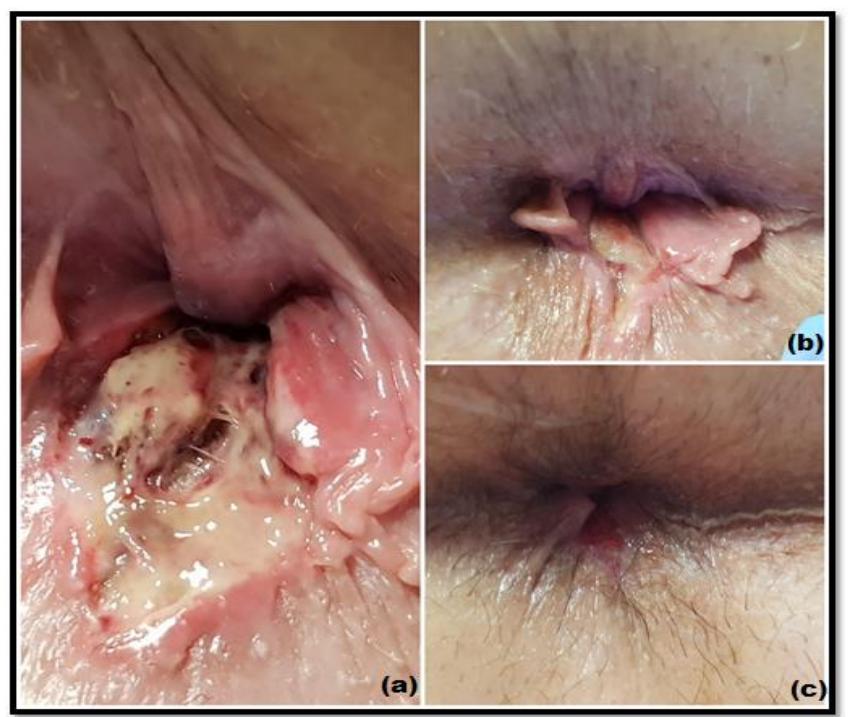

Figure 1: A) Wound after 7 days; B) Wound after 15 days; C) Wound after 22 days 


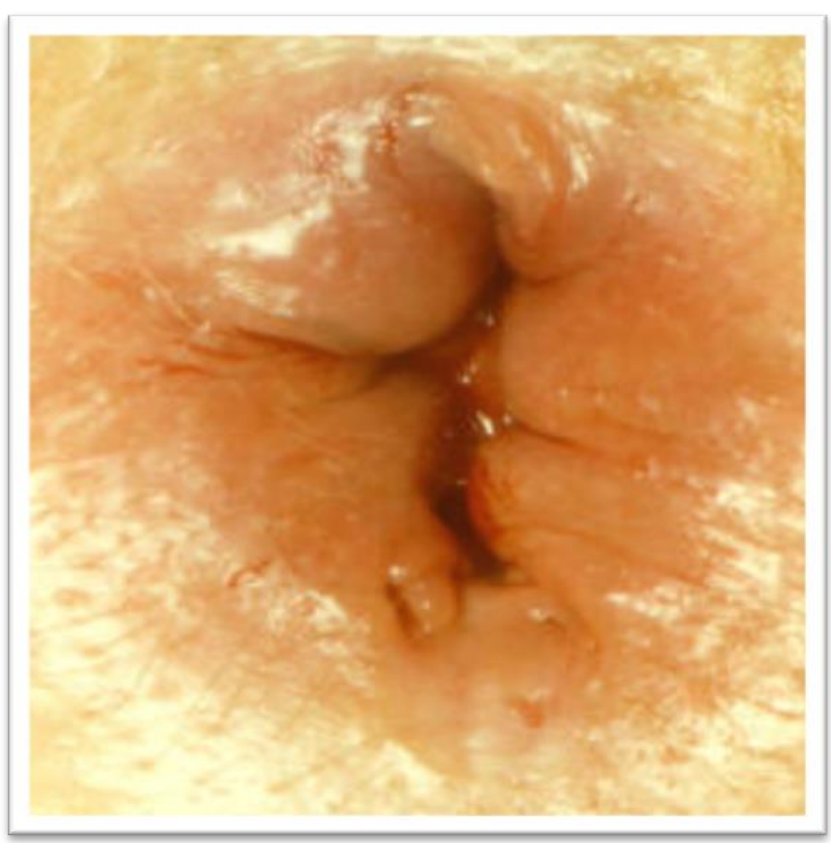

Figure 2: D) Wound after 30 days

\section{Discussion}

HD is a growing health condition affecting millions of people around the world ${ }^{[11]}$. The actual aim is to mitigate post-operative symptoms in those patients in which the preoperative anatomoclinical condition required to perform an excisional haemorrhoidectomy according Milligan-Morgan (MM) ${ }^{[12]}$.

In the MM technique, the wounds are left open for healing by a secondary mechanism and, until it is completely reepithelialized requiring almost 3-5 weeks, patients usually experience pain and intense discomfort that improve over the weeks. ${ }^{[13]}$. However, post-operative pain still remains one of the main problem which may affect patients' quality of life ${ }^{[14]}$ and frequently induce the patients to postpone the procedure. Moreover, pain in association with bleeding and anal stricture represents the most frequent complications after MM, which may require re-intervention in the short or long term ${ }^{[15]}$.

Over the years, proctologists have considered many medical and surgical options to reduce the post-operative pain, up to perform an internal lateral sphincterotomy ${ }^{[7]}$.

In this context, plant extracts and oils became always more relevant and present in the current medical clinical practice. Among the wide group of natural products, it was shown that bioactives compound derived from bergamot have relevant antiinflammatory and vasoprotective properties, helping and supporting haemorrhoidal tissue ${ }^{[9]}$.

Hyaluronic acid, which is present in most of human tissues, contributes to maintain hydration, turgidity and viscosity. It has been involved in several processes as tissue regeneration and matrix organization. It has been observed that local administration is effective helping wounds healing due to the barrier effect protecting the injured epithelium ${ }^{[16,17]}$.

Besides, a recente paper ${ }^{[18]}$ clearly showed that in highgraded HD there are higher levels of matrix metalloproteinases (MMPs), which regulate extracellular structural proteins and tissue remodeling, and Neutrophil gelatinase-associated lipocalin (NGAL), which is involved in the regulation of MMP activity; NGAL is commonly known as a marker of neutrophil activation which can be induced by several cytokines and growth factors. It is common opinion for a long time that degradation of the extracellular matrix is involved in the etiopathogenesis of HD ${ }^{[19]}$.
Benebeo Gel®, by reducing the pro-inflammatory cytokines activation and lowering the intracellular free radicals, prevents the extracellular matrix degradation. It could help in reducing the postoperative aedema and pain, in order to have a faster post-operative recovery.

The present study aimed to evaluate the efficacy of a new topical gel mainly composed by bergamot-derived flavonoids and hyaluronic acid in patients treated with excisional hemorrhoidectomy. The results after 2 weeks of treatment seems to be promising with a very good clinical outcome and patient satisfaction within 1 month. The investigational product showed a good profile of tolerability, safety and efficacy without any major adverse events associated with the use of the new product.

Hence, the treatment of post-hemorrhoidectomy wound with bergamot-derived gel should be recommended to get a quick healing with subsequent pain reduction and faster return to normal activity.

\section{Ethics approval and consent to participate}

Regional Ethics Committee for clinical trials of the Tuscany region. Prot. $N^{\circ} 22207$ Pisa 15/04/2019

\section{List of abbreviations}

Milligan-Morgan (MM)

Haemorrhoidal Disease (HD)

Matrix metalloproteinases (MMPs)

Neutrophil gelatinase-associated lipocalin (NGAL)

\section{Conflicts of Interest}

There is no conflict of interest regarding the publication of this paper."

\section{Funding Statement}

None

\section{Author Contributions}

Conceptualization, D.C. and G.N.; writing-original draft preparation, D.C. and A.S.: Methodology and Validation, L.O. Writing-Review and Editing, A.C. and M.S.S.; Supervision, G.N. All authors have read and agreed to the published version of the manuscript

\section{References}

[1] S. Riss et al., "The prevalence of hemorrhoids in adults," Int. J. Colorectal Dis., vol. 27, no. 2, pp. 215-220, 2012.

[2] G. Gallo, R. Sacco, and G. Sammarco, "Epidemiology of hemorrhoidal disease," Coloproctology, vol. 2, pp. 3-7, 2018.

[3] V. Lohsiriwat, "Hemorrhoids: From basic pathophysiology to clinical management," World J. Gastroenterol., vol. 18, no. 17, pp. 2009-2017, 2012.

[4] G. Gallo et al., "Consensus statement of the Italian society of colorectal surgery (SICCR): management and treatment of hemorrhoidal disease," Tech. Coloproctol., vol. 24, no. 2, pp. 145-164, 2020.

[5] D. F. Altomare et al., "Surgical management of haemorrhoids: an Italian survey of over 32000 patients 
over 17 years," Color. Dis., vol. 20, no. 12, pp. $1117-$ 1124, 2018.

[6] L. Heyerick et al., "Thunderbeat-Assisted Hemorrhoidectomy in Symptomatic Prolapsing Hemorrhoids: A Pilot Trial,” Surg. Innov., vol. 27, no. 3, pp. 311-312, 2020.

[7] A. Medina-Gallardo, Y. Curbelo-Peña, X. De Castro, P. Roura-Poch, J. Roca-Closa, and E. De Caralt-Mestres, "Is the severe pain after Milligan-Morgan hemorrhoidectomy still currently remaining a major postoperative problem despite being one of the oldest surgical techniques described? A case series of 117 consecutive patients," Int. J. Surg. Case Rep., vol. 30, pp. 73-75, 2017.

[8] C. Simillis, S. N. Thoukididou, A. A. P. Slesser, S. Rasheed, E. Tan, and P. P. Tekkis, "Systematic review and network meta-analysis comparing clinical outcomes and effectiveness of surgical treatments for haemorrhoids," Br. J. Surg., vol. 102, no. 13, pp. 16031618, 2015.

[9] D. Cafaro, F. Celedon, S. Sturiale, and M. S. Sincropi, "Innovative results in the treatment of inespecific anusitis-proctitis with the use of bergamot gel (Benebeo gel)®," Insights Clin. Cell. Immunol., vol. 3, no. 1, pp. 020-024, 2019.

[10] D. Cafaro, A. Sturiale, V. Fortuna, S. Ms, and G. Naldini, "Clinical effect of the bergamot-derived gel ( Benebeo gel () associated with mesalazine for the treatment of anitis and proctitis," vol. 1, no. 2, pp. 1-3, 2018.

[11] P. Sheikh, C. Régnier, F. Goron, and G. Salmat, "The prevalence, characteristics and treatment of hemorrhoidal disease: Results of an international web-based survey," J. Comp. Eff. Res., vol. 9, no. 17, pp. 1219-1232, 2020.

[12] G. Naldini et al., "Improvement in Hemorrhoidal Disease Surgery Outcomes Using a New Anatomical/ClinicalTherapeutic Classification (A/CTC)," Surg. J., vol. 06, no. 03, pp. e145-e152, 2020.

[13] C. Simoglou, L. Simoglou, D. Babalis, and D. Gimnopoulos, "Milligan - Morgan haemorrhoidectomy Complications," Hell. J. Surg., vol. 86, no. 2, pp. 68-71, 2014.

[14] H. J. Gerbershagen, S. Aduckathil, A. J. M. van Wijck, L. M. Peelen, C. J. Kalkman, and W. Meissner, "Pain
Intensity on the First Day after Surgery," Anesthesiology, vol. 118, no. 4, pp. 934-944, 2013.

[15] A. A. Abo-hashem, A. Sarhan, and A. M. Aly, "Harmonic Scalpel ${ }^{\circledR}$ compared with bipolar electrocautery hemorrhoidectomy: A randomized controlled trial,” Int. J. Surg., vol. 8, no. 3, pp. 243-247, 2010.

[16] A. Surjushe, R. Vasani, and D. Saple, "Aloe vera: A short review," Indian J. Dermatol., vol. 53, no. 4, pp. 163-166, 2008.

[17] N. G. Sturiale A, Gallo G, Brusciano L, Cacace C, Cafaro D, Celedon Porzio F, "Safety and Efficacy of Proctosoll Allevia in the Management of Haemorrhoidal Disease in Adults: A Prospective Randomized Clinical Trial," Rev. Recent Clin. Trials, vol. 15, no. 2, p. 8, 2020.

[18] R. Serra et al., "Hemorrhoids and matrix metalloproteinases: A multicenter study on the predictive role of biomarkers," Surg. (United States), vol. 159, no. 2, pp. 487-494, 2016.

[19] M. V. Fargo and K. M. Latimer, "Evaluation and management of common anorectal conditions," Am. Fam. Physician, vol. 85, no. 6, pp. 624-630, 2012.

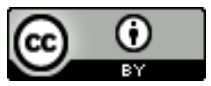

Open Access This article is licensed under a Creative Commons Attribution 4.0 International License, which permits use, sharing, adaptation, distribution and reproduction in any medium or format, as long as you give appropriate credit to the original author(s) and the source, provide a link to the Creative Commons license, and indicate if changes were made. The images or other third party material in this article are included in the article's Creative Commons license, unless indicated otherwise in a credit line to the material. If material is not included in the article's Creative Commons license and your intended use is not permitted by statutory regulation or exceeds the permitted use, you will need to obtain permission directly from the copyright holder. To view a copy of this license, visit https://creativecommons.org/licenses/by/4.0/.

(C) The Author(s) 2021 